\title{
Return of Visual Acuity to Normal in Old Age
}

\section{Misra A}

Department of Ophthalmology

Nepalgunj Medical College Teaching Hospital Kohalpur, Banke

Nepal

Corresponding Author

Anupam Misra

Department of Ophthalmology

Nepalgunj Medical College Teaching Hospital Kohalpur, Banke

Nepal

E-mail: anupam_61@yahoo.com

Citation

Misra A. Return of Visual Acuity to Normal in Old Age. Kathmandu Univ Med J 2013;42(2):165-167.

\begin{abstract}
Changes occur in our body through out life. Decreased visual acuity is probably the most common effect of age-related anatomical and neurological changes in the eyes and the visual pathway. However, this case is an exception as at the age of 75 years, his power of accommodation has returned to normal. The improvement in accommodation and visual acuity is hard to explain. Likely explanations given need to be further investigated.
\end{abstract}

\section{KEY WORDS}

Aging, accommodation visual acuity, crystalline lens, fundus, cortical plasticity

\section{INTRODUCTION}

Changes occur in our body throughout life, as we grow old. Human visual system also experiences impairing changes with older age. Decreased visual acuity is probably the most common effect of anatomical and neurological changes in older persons. As a result, the visual stimuli with higher contrast are perceived better than those with lower contrast. In general older eyes are more susceptible to common age-related diseases, such as macular degeneration, cataract and glaucoma. Unfortunately most of the elderly people can not distinguish between normal vision loss and disease related loss; so, they do not seek professional care. ${ }^{1}$

The age related anatomical changes include changes in the cornea, crystalline lens, pupil, vitreous humor, retina, and the retinal pigment epithelium. Thickening of cornea, loss of flexibility of crystalline lens, changes in the chemical composition of lens, and smaller pupillary diameter have been reported to occur in older people. ${ }^{2-4}$ The changes in lens and pupil reduce the amount of light that the eyes receive. The older eyes thus require more light. Poor contrast sensitivity makes the boundary detection difficult. ${ }^{5}$ The cells of retinal pigment epithelium become irregular. ${ }^{6}$ There is a decrease in the capacity of retinal pigment epithelium to absorb light, causing glare. ${ }^{2}$

Visual perception relies on the visual pathway. Old age changes in the visual pathway include loss of retinal cells, loss of neurons, and secretion of abnormal proportions of neurotransmitters which affects the neuronal communication in the visual pathway. ${ }^{4}$

\section{CASE-REPORT}

A 75 year old male reported in the Out Patient Department (OPD) with a request for refraction as he had accidentally broken his pair of spectacles a few weeks earlier. He wanted the refraction to be done before going for a new pair of spectacles. When enquired, he informed that he is a non-smoker, non-alcoholic, strict vegetarian for the last 15 years, leads an active life and goes on regular evening walk. 
He is continuing service as he has taken up an employment after retirement. He is still driving his car without any vision related difficulty. Health wise, he is non-diabetic, non-hypertensive and is not taking any treatment for any chronic ailment. His blood pressure remains within normal limits. The only age-related problem that he has suffering was impairment of hearing for nearly last five years. On the whole his physical and mental health was good.

He started using glasses for distant vision at the age of about 41 years. Subsequently, presbyopic changes started developing, as he started using bifocal lenses at the age of about 50 years. The power of bifocal lenses uses by him are given below:

Table 1. Power of bifocal lenses.

\begin{tabular}{ll} 
Right eye & $0.50 \mathrm{D}$ cylinder $\times 50^{\circ}$ \\
\hline Left eye & $0.25 \mathrm{D}$ sphere / - $0.50 \mathrm{D}$ cylinder $\times 115^{\circ}$ \\
\hline Presbyopic correction & Both eyes + 3 D
\end{tabular}

Since then he had regularly been using bifocal lenses until his spectacles were broken. He managed without spectacles for 3-4 weeks during which period he did not experience much difficulty and even drove his car without glasses.

\section{Observations}

When refraction was done, it was found, that both his distance vision as well as near vision were normal. The refraction was repeated.

Table 2. Visual acuity.

\begin{tabular}{lll}
$\begin{array}{lll}\text { Distance vision as recorded using Snel- } \\
\text { len's Test Type }\end{array}$ & $\begin{array}{l}\text { Right eye } \\
\text { Left eye }\end{array}$ & $6 / 6$ \\
$\begin{array}{lll}\text { Near vision as recorded on Faculty of } \\
\text { Ophthalmologists of Britain Test Chart }\end{array}$ & Right eye & N / 5 \\
\hline & Left eye & N / 5
\end{tabular}

Both visual acuities were without correction

Following refraction findings, routine examination of both eyes was done. On examination it was found as below.

Table 3. Routine bilateral examination of eyes.

\begin{tabular}{|c|c|c|}
\hline Cornea & Both eyes & healthy and transparent \\
\hline Pupils & Both eyes & $\begin{array}{l}\text { showed slight constric- } \\
\text { tion (senile miosis) }\end{array}$ \\
\hline \multirow[t]{2}{*}{ Crystalline lens } & Right eye & No cataractous change \\
\hline & Left eye & No cataractous change \\
\hline \multirow{2}{*}{$\begin{array}{l}\text { Intraocular pressure by } \\
\text { Applanation Tonometry }\end{array}$} & Right eye & 12 \\
\hline & Left eye & 14 \\
\hline
\end{tabular}

Fundus Examination - The bilateral fundus examination was done and the following were observed:

Routine investigation done:

- Blood Pressure : 130/82

- Fasting blood sugar : 88mgm. / 100 ml. of blood
Table 4. Fundus examination.

\begin{tabular}{lll} 
Media & Both eyes & Clear \\
\hline Optic discs & Both eyes & Normal \\
\hline Foveal Reflex & Both eyes & Sharp \\
\hline Blood vessels & Both eyes & Normal \\
Background & Both eyes & Normal \\
\hline
\end{tabular}

- Hemoglobin : $15.5 \mathrm{gm} / 100 \mathrm{ml}$. of blood

-T.L.C. : 2,800 / cu. ml. of blood

- D.L.C.

Neutrophil $-72 \%$

Lymphocyt- $23 \%$

Monocyt- 03\%

Eosinophi- $02 \%$

\section{DISCUSSION}

The return of visual acuity to normal in a person 75 years old, who had been using spectacles for nearly 35 years, is hard to explain. Changes in the human visual system due to aging have been described and decreased visual acuity is probably the most common effect of anatomical and neurological changes in older persons.

Thickening of cornea in old age has been described by Oberlink where as in our patient the corneas of both the eyes were found to be healthy and transparent. ${ }^{2}$ The loss of flexibility of the center of crystalline lens as well as changes in the chemical composition of the lens has been reported by Spector. ${ }^{3}$ These chemical changes cause the lens to become yellowish. However, in our patient the lens were surprisingly found to be clear and transparent. Slight miosis was seen in our patient who is in conformity with Ordy, Brizzee and Johnson who have described decrease in the size of pupillary diameter. ${ }^{4}$ Upon fundus examination, we did not find any abnormality in the retina, although it has been reported by Marmor6 that the cells of the retinal pigment epithelium become irregular. Pastalan has reported that poor contrast sensitivity makes the boundary detection difficult in old age. ${ }^{5}$ In contradiction the visual acuity was found to be normal in our patient, which suggests that in this case there was no such difficulty.

The findings in this case suggest that earlier age related changes either somehow got resolved or compensatory changes occurred later which might have made up for the earlier deficiencies in visual functions. As a result the visual functions returned to normal. There are two possible explanations for the unexpected improvement and return of visual acuity to normal. One of the explanations could be cortical plasticity. Plastic changes in the nervous system are known to occur from one sensory modality to another. For example, deaf individuals respond faster to normal stimuli in the visual periphery. ${ }^{7}$ Thus it is quite possible that in this patient the auditory cortex, which is not being 
put to great use due to impairment of hearing, might have started helping in the visual functions. The other possibility is that some enzymatic changes in the neurochemistry of visual pathway might have caused resolution of structural and functional changes that might have occurred earlier in the patient. Still another possibility could be that the visual functions was maintained because the patient was not suffering from common age-related health problems like diabetes, hypertension, Alzheimer's disease etc. and is maintaining good health.

\section{CONCLUSION}

The usual age related visual changes need not necessarily occur with the same severity in every individual. General health of a person seems to be an important factor affecting the onset and course of the changes in the visual functions. If the age related changes are not severe they may show improvement and functions may probably return to normal. More such cases need to be studied and investigated.

\section{REFERENCES}

1. Silverstone, B. Beyond the boundaries of normal aging. The case of age-related vision loss. Gerontologist 1993;33: 566 - 567.

2. Oberlink, M. Keeping an eye on vision: Primary care of age-related ocular disease. Geriatrics 1997;52: 30-37.

3. Spector, A. Aging of the lens and cataract formation. In R. Sekuler, D. Kline, and K.Dismukes(Eds.). Aging and human visual function. New York,N.Y: Alan R Liss, Inc; 1982.p30-43.

4. Ordy J.M, Brizzee K.R, Johnson H.A. Cellular alterations in visual pathways and limbic system: implications for vision and short - term memory. In R. Sekuler; D. Kline and K. Dismukes (Eds.). Aging and human visual function. New York, NY: Alan R. Liss, Inc; 1982.p79-114.

5. Pastalan, L.A. Environmental design and adaptation to the visual environment of the elderly. In R. Sekuler, D. Kline and K. Dismukes (Eds.) Aging and human visual function. New York, NY: Alan R Liss, Inc; 1982.p323-333.

6. Marmor, M.F. Aging and the retina. In R. Sekuler, D.Kline, and K.Dismukes (Eds.). Aging and human visual function. New York., NY: Alan R Liss, Inc.1982:59-78.

7. Kim,E.B, Susan M, Scott B, Heddwen L. B. In Ganong's Review of Medical Physiology. 23rd edition. Cortical plasticity;2010:176. 